\section{The secret that patients will love!}

Discreet orthodontic lingual appliances are a perfect way to help patients who are concerned that braces could impact their smiles during treatment.

So why not choose one of the most trusted discreet appliances in the industry - the Incognito Appliance System from 3M Oral Care.

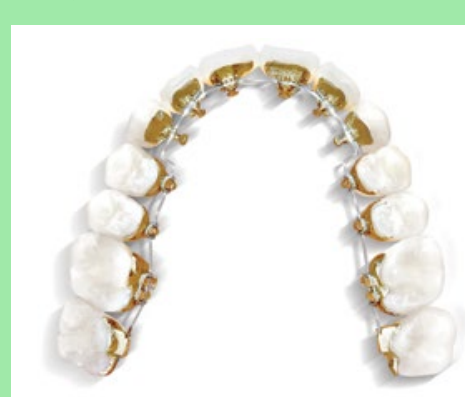

Completely custom-made to every individual, this innovative system is placed behind the teeth and remains hidden from view during treatment. Furthermore, as every part of the Incognito Appliance System is completely bespoke, this ensures that clinicians are able to achieve predictable, controlled outcomes.

For more information call 08458734066 or visit http://solutions.3m.co.uk/wps/portal/3M/en_GB/ orthodontics_EU/Unitek/.

\title{
Committed to your success
}

Clark Dental has been supporting dental professionals from across the UK for over 44 years, offering a bespoke surgery design and equipment supply service.

No matter your budget or preferences, the Clark Dental team can offer you the latest solutions to meet your professional needs. They have the expertise to plan and manage your project, working closely with you to design and install the practice of your dreams.

Clark Dental's commitment to your success doesn't simply stop there. The friendly team also offer an exceptional after-sales service, including dedicated technical support to ensure you make the most of your investment.

Call Clark Dental for all your practice transformations on 01268733 146, email info@ clarkdental.co.uk or visit www.clarkdental.co.uk.
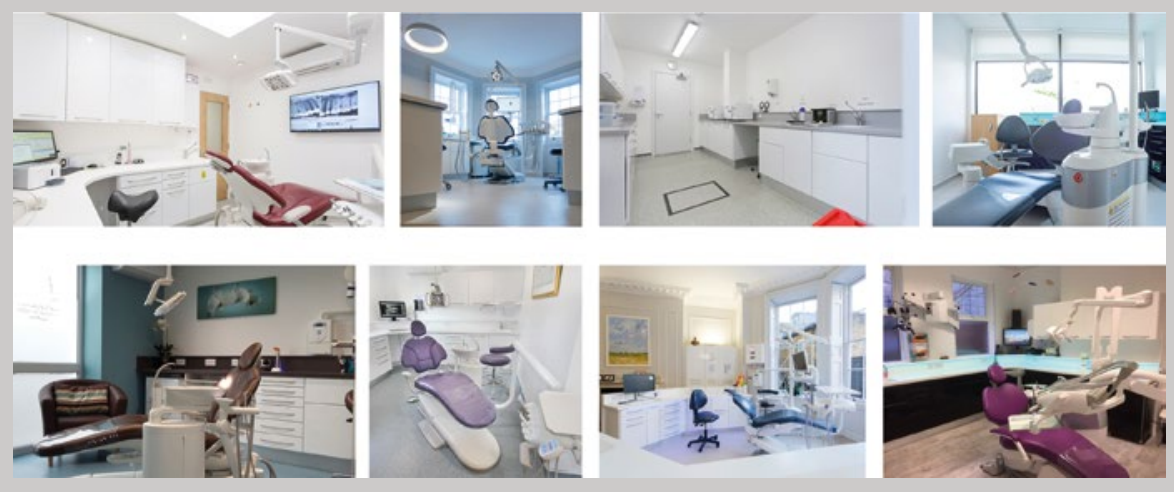

\section{The preferred implant}

For unparalleled outcomes in your dental implant cases, choose an effective solution that mimics the function and aesthetic of a natural tooth. The $\mathrm{Z} 1$ tissue-level implant manufactured by TBR combines a titanium body with a unique zirconia collar.

This innovative design enables you to place the $Z 1$ in one surgical step to ensure a more comfortable treatment experience for both patient and practitioner. The Z1 also promotes regeneration of the soft and hard tissue simultaneously for accelerated healing, which not only offers time-saving benefits but also ensures an outstanding result.

For more information on the $\mathrm{Z} 1$ implant, visit tbr.dental, email support@denkauk. com or call 08007076212 .
Fight back against

\section{hard water}

Did you know that hard water can considerably impact the lifetime of important equipment such as your autoclave? Calcium deposits quickly build up inside pipework and around heating elements causing blockages and damage to key components or, worse still, complete system failure.

Combat this by installing the Reverse Osmosis (RO) Water System from Eschmann.

This device supplies medical grade reverse osmosis water for your surgery and decontamination equipment, removing excess calcium and other impurities so that you can benefit from clean, pure water.

Compact and easy to fit, this system is also a faster, more efficient way to produce pure water than a traditional water distiller.

For more information on the highly effective and affordable range of decontamination equipment and products from Eschmann, visit www. eschmann.co.uk or call 01903875787.

\section{Speed up reprocessing}

W\&H aims to help clinicians optimise their handpiece maintenance procedures with the Assistina TWIN, which features two chambers that can be used alternately to speed up reprocessing.

The Assistina TWIN nebulises the oil to produce a dispersible mist that is discharged through the handpiece at high pressure. This not only removes contamination from within the instrument, but also ensures even the most inaccessible parts are consistently coated.

Spray channels can be cleaned and components oiled in just 10 seconds per handpiece, enabling you to process up to 360 instruments per hour.

To find out more visit www.wh.com/ en_uk, call 01727874990 or email office. uk@wh.com. 